human EGF receptor, which comprises 542 amino acids ${ }^{12}$.

The extracellular domain, which contains the transferrin binding site, comprises 648 amino acids. This domain contains three of the five possible sites for asparagine-linked glycosylation (Asn-X-Ser/Thr). As endoglycosidase digestion experiments have indicated that the receptor contains three $\mathrm{N}$-linked glycan units, all three of these asparagines must be glycosylated.

Eight cysteine residues are distributed throughout the transferrin receptor sequence. Four cysteines are found in the region of the transbilayer peptide; two flank the peptide, one resides within the putative transbilayer sequence, and one is located close to the bilayer on the extracellular side. The remaining cysteines are present in two clusters in the extracellular domain (Fig. 4). It is unknown whether any of these cysteine residues form intrachain disulphide bridges. However, at least one must form the interchain disulphide bond(s) between the two 90,000 MW receptor subunits. Protein biochemical data suggest that the intersubunit disulphide bond(s) must lie close to the cell membrane, as trypsin treatment releases a non-disulphidelinked, 70,000-MW fragment from the cell surface ${ }^{5}$. It is unlikely that the cysteine (residue 62) on the cytoplasmic domain is disulphide-bonded due to the strong reducing environment of the cytoplasm. The cluster of three cysteines close to or in the bilayer are, therefore, the most likely candidates for making an interchain disulphide bond.

The amino-terminus of the transferrin receptor contains no obvious signal sequence. This observation is consistent with in vitro translation experiments in which the size of the primary translation product is indistinguishable from that of the endoglycosidase $\mathrm{H}$-treated polypeptide synthesized in the presence of microsomes ${ }^{10}$. The lack of an $\mathrm{N}$-terminal cleavable signal sequence is not unprecedented. No such signal sequence has been identified in the Ia-associated invariant polypeptide, which also has the reverse orientation in the plasma membrane ${ }^{17}$. Similarly, the secreted glycoprotein ovalbumin has been shown to contain an internal signal sequence ${ }^{20}$. It is possible that the transbilayer sequence of the human transferrin receptor performs the dual function of acting as a signal sequence and of anchoring the protein in the plasma membrane.

When the amino acid sequence of the transferrin receptor was used in a search of the Dayhoff data base, no strong homology with any known protein was revealed. There is some homology with the EGF precursor and with the chicken transferrin precursor, but the degree of homology is very low (see Fig. 3 legend). Similarly, a search of a more specialized data base containing a comprehensive collection of oncogene sequences (G. Scrace, personal communication) revealed no strong homologies.

We thank Hiro Mahbubani for technical assistance, Michael Green for performing secondary structure analysis of the protein, and I. Stabinsky for providing the synthetic oligonucleotide described in the text. We also thank G. Scrace, J. Downward, R. Sutherland, M. Greaves and M. Waterfield for allowing us access to protein sequence data in advance of publication, and Rita Harris and Brenda Marriott for their help in preparing the manuscript. C.S. is on leave of absence from the Institute of Biochemistry, University of Trieste, Trieste 34127, Italy.

Received 30 July; accepted 7 September 1984.

1. Newman, R., Schneider, C., Sutherland, R., Vodinelich, L. \& Greaves, M. Trends biochem. Sci. 1, $397-400$ (1982)

2. Hopkins, C. R. \& Trowbridge, I. S. J. Cell Biol, 97, 508-521 (1983)

3. Dautry-Varsat, A., Ciechanover, A. \& Lodish, H. F. Proc. natn. Acad. Sci. U.S.A. 80 , 2258-2262 (1983).

4. Goldstein, J. L., Anderson, R. G. W. \& Brown, M. S. Nature 279, 679-685 (1979).

5. Schneider, C., Sutherland, R., Newman, R. \& Greaves, M. J. biol. Chem. 257, 8516-8522 (1982).

6. Trowbridge, I. S. \& Omary, M. B. Proc. natn. Acad. Sci. U.S.A. 78, 3039-3043 (1981)

7. Omary, M. B. \& Trowbridge, I. S. J. biol. Chem. 256, 12888-12892 (1981)

8. Schneider, C., Kurkinen, M. \& Greaves, M. EMBO J. 2, 2259-2263 (1983).

9. Kühn, L. C., McClelland, A. \& Ruddle, F. H. Cell 37, 95-103 (1984)

10. Schneider, C., Assen, U., Sutherland, R. \& Greaves, M. F. FEBS Lett. 158, 259-264 (1983).

11. Kozak, M. Nucleic Acids Res, 9, 5233-5252 (1981).

12. Ullrich, A. et al. Nature 309, 418-425 (1984)

13. Lodish, H. F., Braell, W. A., Schwartz, A. L., Straus, G. J. A. M. \& Zilberstein, A. Int. Rev. Cytol. 12, 247-307 (1981).
14. Drickamer, K. L. J. biol. Chem. 256, 5827-5839 (1981).

15. Drickamer, K. L. J. biol. Chem. 253, 7242-7248 (1978)

16. Singer, P. A. et al. EMBO J. 3, 873-877 (1984)

17. Claesson, L., Larhammar, D., Rask, L. \& Peterson, P. A. Proc. natn. Acad. Sci. U.S.A. 80, $7395-7399$ (1983)

18. Kaufman, J. F., Krangel, M. S. \& Strominger, J. L. J. biol. Chem. 259, 7230-7238 (1984)

19. Blobel, G. Proc. natn. Acad. Sci. U.S.A. 77, 1496-1500 (1980).

20. Braell, W. A. \& Lodish, H. F. J. biol. Chem. 257, 4578-4582 (1982).

21. Gubler, U. \& Hoffman, B. J. Gene 25, 263-269 (1983).

22. Devine, J. M., Tsang, H. \& Williams, J. G. Cell 28, 793-800 (1982).

23. Messing, J. \& Vieira, J. Gene 19, 269-276 (1982).

24. Dente, L., Cesareni, G. \& Cortese, R. Nucleic Acids Res. 11, 1645-1655 (1983).

25. Kyte, J. \& Doolittle, R. F. J. molec. Biol. 157, 105-132 (1982).

26. Wilbur, W. T. \& Lipmann, D. Proc, natn Acad. Sci. U.S.A. 800, 726-730 (1983).

27. Sanger, F., Nicklen, S. \& Coulson, A. R. Proc. natn. Acad. Sci. U.S.A. 74, 5463-5467 (1977).

28. Maxam, A. M. \& Gilbert, W. Methods Enzymol. 65, 499-560 (1980).

\section{Three-dimensional structure of an antigenic mutant of the influenza virus haemagglutinin}

\author{
M. Knossow* $\ddagger$, R. S. Daniels $\dagger$, A. R. Douglas $\dagger$, \\ J. J. Skehelt \& D. C. Wiley*
}

\begin{abstract}
* Department of Biochemistry and Molecular Biology, Harvard University, Cambridge, 02138, USA

$\dagger$ National Institute of Medical Research, Mill Hill, London NW7 IAA, UK
\end{abstract}

Antigenic variation in the haemagglutinin (HA) glycoprotein of influenza virus is associated with recurrent epidemics of respiratory disease in man (for review see ref. 1). We have examined the size of structural changes necessary to alter the antigenicity of $\mathrm{HA}$ by determining the three-dimensional structure of the HA from an antigenic mutant containing a single amino acid substitution which was selected by growth of virus in the presence of monoclonal antibodies. Here we present evidence that the simple addition of an amino acid side chain which results in only minor local distortions of the structure of the HA is sufficient structural alteration for a virus to escape neutralization by a monoclonal antibody. Our results also demonstrate that single amino acid substitutions can cause only local changes in the HA structure, verifying the assumption made in several studies to locate antigenic sites on the $\mathbf{H A}^{2-5}$ and other molecules ${ }^{6,7}$, and indicate that proposals ${ }^{8,9}$ of large conformational changes to account for variations in HA antigenicity are unnecessary in this case. The structure of the variant antigen has independently been successfully predicted (M. Karplus, personal communication).

An antigenic variant, $\mathrm{V} 3 \mathrm{a}$, was selected by growing the parent (X31) virus ${ }^{10}$ in the presence of a neutralizing monoclonal antibody, $\mathrm{HC} 3 \mathrm{a}$, as described previously ${ }^{11,12}$. Table 1 shows that while haemagglutination by the parent virus is inhibited by $\mathrm{HC} 3 \mathrm{a}$ ascitic fluid at a dilution of $1: 12,800$, the variant virus $\mathrm{V} 3 \mathrm{a}$ is not inhibited at a 1:100 dilution of the fluid. A similar result was obtained in enzyme-linked immunosorbent antibody binding asșays, in which parent virus and V3a mutant virus bound antibodies at ascitic fluid dilutions of $1: 100,000$ and $1: 100$, respectively.

The amino acid sequence of the entire V3a HA was determined by sequencing the viral RNA using methods described previously $^{13,17,18}$; only one nucleotide change was observed, $G$ to $A$, at nucleotide 514 which, when translated into amino acids, established that V3a has an aspartic acid at position 146 in the HA1 polypeptide instead of the glycine in the parental sequence $^{19}$

Isomorphous crystals of $\mathrm{V} 3 \mathrm{a}$ were grown under conditions in which the X31 HA crystallizes ${ }^{14}$. (This has been observed for all of four single amino acid variants tested to date.) We collected 76,840 unique X-ray reflections to $3.0 \AA$ resolution on $1^{\circ}$ oscillation photographs recorded at $4^{\circ} \mathrm{C}$ by methods described previously ${ }^{15}$. Partially recorded reflections $(\geq 50 \%)$ were included in the data set after adjustment by the post-refinement pro-

¥ Present address: Laboratoire de Physique, Centre Pharmaceutique, 92290 Chatenay-Malabry, France. 
Fig. 1 A schematic diagram of a monomer of the haemagglutinin from the 1968 Hong Kong influenza virus ${ }^{15}$, showing the location of the single mutation, Gly to Asp 146.

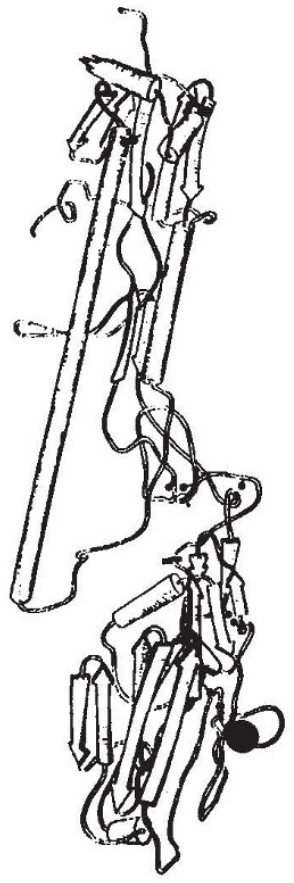

Although multiple amino acid substitutions in the HA appear to be necessary for a virus to acquire the potential to cause an epidemic $^{2}$, single amino acid substitutions in the HA are sufficient for a virus to escape neutralization by monoclonal antibodies ${ }^{11}$. The three-dimensional structure of the HA of an antigenic variant presented here indicates that the substitution of an aspartic acid for a glycine, without any significant changes in the positions of the atoms in the rest of the HA molecule, is a sufficient alteration to reduce by three orders of magnitude the binding of a monoclonal antibody. The absence of other structural changes in the variant $\mathrm{HA}$, in turn, proves that the monoclonal antibody used to select this variant must bind directly to the region of the HA surface designated site A by Wiley et al. $^{2}$.

Since submitting this manuscript we have found that H. H.-L. Shih, J. Brady and M. Karplus (unpublished) have independently and with no prior knowledge of our results successfully predicted the structural changes in the mutant $\mathrm{V} 3 \mathrm{a}$, relative to the parent protein. Using a perturbation approach making use of the empirical energy function program CHARMM ${ }^{23}$, they calculated a conformational potential energy surface ${ }^{24}$ for the aspartic acid side chain in the presence of the rest of the protein. Energy refinement ${ }^{23}$ of the low energy conformations on this surface yielded side chain torsion angles for Asp 146 with $\pm 20^{\circ}$ of the X-ray results. Further, the prediction of an adjustment

Table 1 Haemagglutination-inhibition reactions of $\mathrm{X} 31$ virus and antigenic mutant V3a (the aspartic acid and glycine side chains may directly affect the binding affinity. (2) The aspartic acid 146-arginine 141 interaction may stabilize the local structure of the site to which the monoclonal antibody binds, which would decrease the binding affinity if the antibody needed to locally distort or denature the site for tight binding. The former possibility corresponds to the classical 'static' view of an antibody-antigen complex, while the latter would apply if the free energy decrease on binding to a distorted site were greater than that required to distort the site. Present knowledge about the state of an antigen when 'seen' by immunogenic lymphocytes during the generation of an immune response and about the structure of an antigen-antibody complex leaves both possibilities feasible. In the case of V3a, the electrostatic charge of the Asp side chain would lead to unfavourable charge interactions (the burying of an unpaired charge) in complexes with antibodies against the parent (Gly).

\begin{tabular}{lrrrrr}
\multicolumn{5}{c}{ genic mutant V3a } \\
\hline Virus & HC3a & HC31 & HC101 & HC83 & HC263 \\
X31 & 12,800 & 6,400 & 12,800 & 6,400 & 25,600 \\
V3a & $>100$ & 6,400 & 12,800 & 6,400 & 25,600 \\
\hline
\end{tabular}

Haemagglutinin-inhibition reactions were done by standard procedures. The values shown are the reciprocals of the highest dilutions of the antibodies at which haemagglutination was inhibited. The specificities of the different monoclonal antibodies are defined by the amino acid substitutions observed in antigenic variants of $\mathrm{X} 31$ virus that the individual antibodies select. Thus, antibody HC3a selects mutants with amino acid substitutions at residue $146 ; \mathrm{HC} 31$ at residue 198; $\mathrm{HC101}$ at residue $63 ; \mathrm{HC} 83$ at residue 193; and $\mathrm{HC} 263$ at residue 158. All monoclonal antibodies tested, other than HC3a which was used to select V3a, react with $\mathrm{X} 31$ and $\mathrm{V} 3 \mathrm{a}$ equally. 

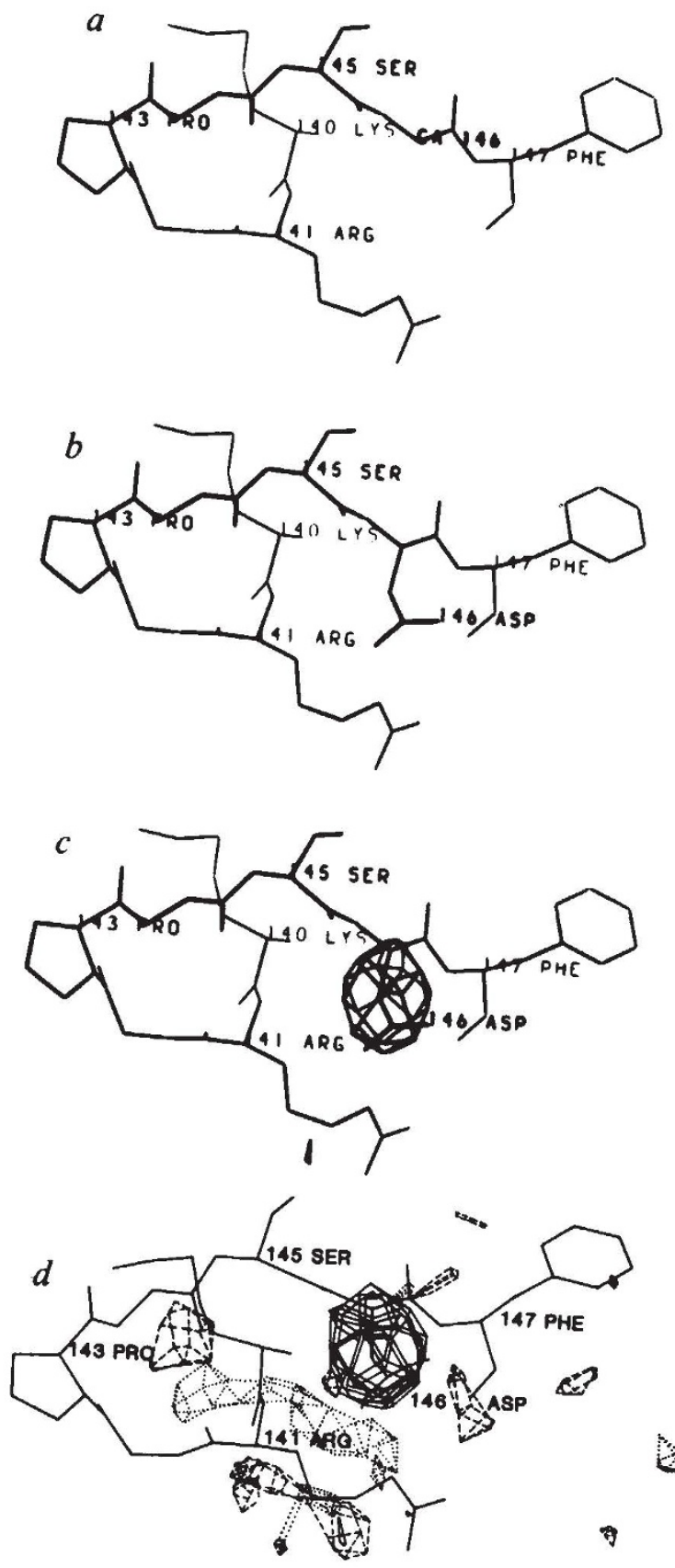

Fig. $2 a$, Structure of the amino acid 140-147 loop which contains a glycine at position 146 in the parent HA. Atomic coordinates for the parent structure ${ }^{15}$ were obtained by model building (I. A. Wilson and D.C.W.) on a version of the BILDER program ${ }^{20}$ modified by Robert Ladner. These were refined to an $R$ factor of 0.26 after six cycles of restrained least-squares refinement ${ }^{21}$ where the contribution of the structure factor to the least-squares equation was evaluated by the gradient-curvature method on a difference map (ref. 22 and M. Lewis and D. Rees, personal communication). $\left(R=\Sigma\left|s i I_{h i}-\bar{I}_{h}\right| / \Sigma \bar{I}_{h}\right)$ where $s i=$ scale factor (including film temperature factor) for crystal $i$, and $I_{h t}=$ intensity of reflection $h$ of crystal $i$.) Exact 3-fold symmetry was imposed on the HA trimer in the crystallographic asymmetric unit by refining only a monomer's coordinates from 3-fold averaged difference maps. An overall $B$ factor of 14 was used. Details of the refinement will be published elsewhere. $b$, The coordinates of the 140-147 loop of the antigenic variant V3a showing the location of the Asp (for Gly) substitution. Note that no conformational changes are observed between $a$ and $b$. The V3a loop coordinates were obtained from model building on a $2 F_{0}-F_{c}$ map after refining the $X 31$ coordinates (minus the loop) against the V3a data. $c$, The V3a difference map ( $\left.F_{\text {obs }} \mathrm{V} 3 \mathrm{a}-F_{\text {obs } \times 31}\right)$ showing the $12 \sigma$ peak at Asp 146. The only significant difference is at the position expected by the addition of the Asp 146 side chain instead of Gly 146 in the wild type. The difference Fourier was calculated using observed parent and variant structure factors with the refined phases described for $a$. $d$, The same as $c$ with additional positive (dashed) and negative (dotted) contours at the noise level, $3 \sigma$. The interpretable $3 \sigma$ peaks are a ridge of difference density indicating a small shift in the position of the side chain of Arg 141, which is within hydrogen bonding distance of Asp 146. (This figure was produced with an Evans and Sutherland PS-300 on the version of FRODO written by J. W. Pflugrath, M. A. Saper, B. Bush and A. Jones.)

4. Daniels, R. S., Douglas, A. R., Skehel, J. J. \& Wiley, D. C. J. gen. Virol. 64, 1657-1662 (1983). 5. Daniels, R. S. et al. in The Origin of Pandemic Influenza Viruses (eds Laver, G. W. \& Chu, C. M.) (Elsevier, New York, in the press).

6. Colman, P. M. Varghese, J. N. \& Laver, W. D. Nature 303, $41-44$ (1983).

7. Evans, D. M. A., Minor, P. D., Schild, G. S. \& Almond, J. W. Nature 304, 459-462 (1983).

8. Laver, W. G., Air, G. M. \& Webster, R. G. in Genetic Variation Among Influenza Viruses (ed. Nayak, D. P.) 283-295 (Academic, New York, 1981).

9. Webster, R. G. \& Laver, W. G. Virology 104, 139-148 (1980).

10. Bull. Whd Hlth Org. 45, 119-124 (1971).

11. Laver, W. G., Air, G. M., Dophiede, T. A. \& Ward, C. W. Nature 283, 454-457 (1980).

12. Skehel, J. J. et al. Proc. natn. Acad. Sci U.S.A. (in the press).

13. Rogers, G. N. et al. Nature 304, 76-78 (1983)

14. Wiley, D. C. \& Skehel, J. J. J. molec. Biol 112, 343-347 (1977)

15. Wilson, I. A., Skehel, J. J. \& Wiley, D. C. Nature 289, 368-373 (1981).

16. Winkler, F. K., Schutt, C. E. \& Harrison, S. C. Acta crystallogr. A35, 901-911 (1979).

17. Sanger, F., Nicklen, S. \& Coulson, A. R. Proc. natn. Acad. Sci. U.S. A. 74, 5463-5467 (1977).

18. Patel, T. P. et al. Nucleic Acids Res. 10, 5605-5620 (1982).

19. Verhoeyen, M. et al. Nature 286, 77 1-776 (1980).

20. Diamond, R. in Biomolecular Structure, Conformation, Function and Evolution Vol. 1 (ed. Srinivasan, R.) 567-588 (Pergamon, Oxford, 1980)

21. Hendrickson, W. A. \& Konnert, J. in Biomolecular Structure, Function, Conformation, and Evolution Vol. 1 (ed. Srinivasan, R.) 43-47 (Pergamon, Oxford, 1980).

22. Cochran, W. Acta crystallogr. 4, 408-411 (1951).

23. Brooks, B. et al. J. comp. Chem. 4, 187-217 (1983)

24. Gelin, B. R. \& Karplus, M. Biochemistry 18, 1256-1268 (1979). in the position of Arg 141 to improve the hydrogen bond to the carboxyl group of Asp 146 led to our finding its displacement in the experimental difference map. Details of the method and results will be given separately.

We thank David Stevens and Rose Gonsalves for assistance, Eugene Brown of Genetic Institute for synthesizing one of the oligonucleotide primers, and acknowledge support from NIH Al 13654 (D.C.W.). M.K. was the recipient of fellowship DRG542 from the Damon Runyon-Walter Winchell Cancer Fund. We also thank Henry H.-L. Shih, John Brady and Martin Karplus for allowing us to quote from their unpublished results predicting the structure of the single-site mutant

\section{Received 25 April; accepted 14 June 1984}

1. Webster, R. G. \& Laver, W. G. in Influenza Viruses and Influenza (ed. Kilbourne, E. D.) 270-314 (Academic, New York, 1975).

2. Wiley, D. C., Wilson, I. A. \& Skehel, J. J. Nature 289, 373-378 (1981).

3. Caton. J. J., Brownlee, C. C., Yewdell, C. A. \& Gerhard, W. Cell 31, 417-427 (1982).

\section{Errata}

\section{A general circulation model of water isotope cycles in the atmosphere}

S. Joussaume, J. Jouzel \& R. Sadourny

Nature 311, 24-29 (1984)

IN this article, the order of the authors was incorrect. It appears correctly above.

\section{Sequential late Cenozoic structural disruption of the northern Himalayan foredeep}

\section{W. Burbank \& R. G. H. Raynolds}

Nature 311, 114-118 (1984)

THE above article was published with the name of the third author spelt incorrectly as Reynolds. 